\title{
The role of ITS in evacuation route choice
}

\author{
M. L. De Maio, G. Musolino \& A. Vitetta \\ DIMET, Dipartimento di Informatica Matematica Elettronica e \\ Trasporti, Università Mediterranea di Reggio Calabria, Italy
}

\begin{abstract}
The paper focuses on Intelligent Transport Systems (ITS) oriented to route choice management and control on urban road transportation networks. The elements of an ITS may be grouped into three functional classes: survey and transmission, control and users information. ITS for survey require an architecture based on sensors located on the network, which detect traffic conditions. ITS for control have their core in the so-called Decision Support Systems (DSS), which may operate both in ordinary and emergency conditions. Emergencies in transport system require a real-time management in order to support decision makers in a dynamic context. ITS for users information allowing dissemination of information to users during their trip. Information may be descriptive or prescriptive in relation to the management strategy adopted. In the paper the description of each functional class considers hardware and software elements.

Keywords: Intelligent Transport System (ITS), route choice, dynamic traffic assignment, emergency conditions.
\end{abstract}

\section{Introduction}

An ITS (Intelligent Transport System) is a set of hardware and software components which allows collecting, processing and disseminating information to improve passengers and freight trips [1]. In relation to route and parking choice [2-5], an ITS provides information to users concerning routes to be followed generally with the aim to reduce travel times and congestion on the network in ordinary conditions. On the other hand in evacuation conditions, information acquired through sensors and indicators obtained by DSS are used by authorities or network managers in order to elaborate descriptive/prescriptive strategies [6]. Several ITS have been developed in literature: a general 
description is presented in Figure 1 according to three functional classes: survey and transmission, control, users' information.

The system depicted in Figure 1 is specified for generic needs. In the following each of the three classes will be specified for needs connected to route choice for individual users on urban road transport network. Two cases will be analysed: the ordinary and the emergency conditions of the transport network.

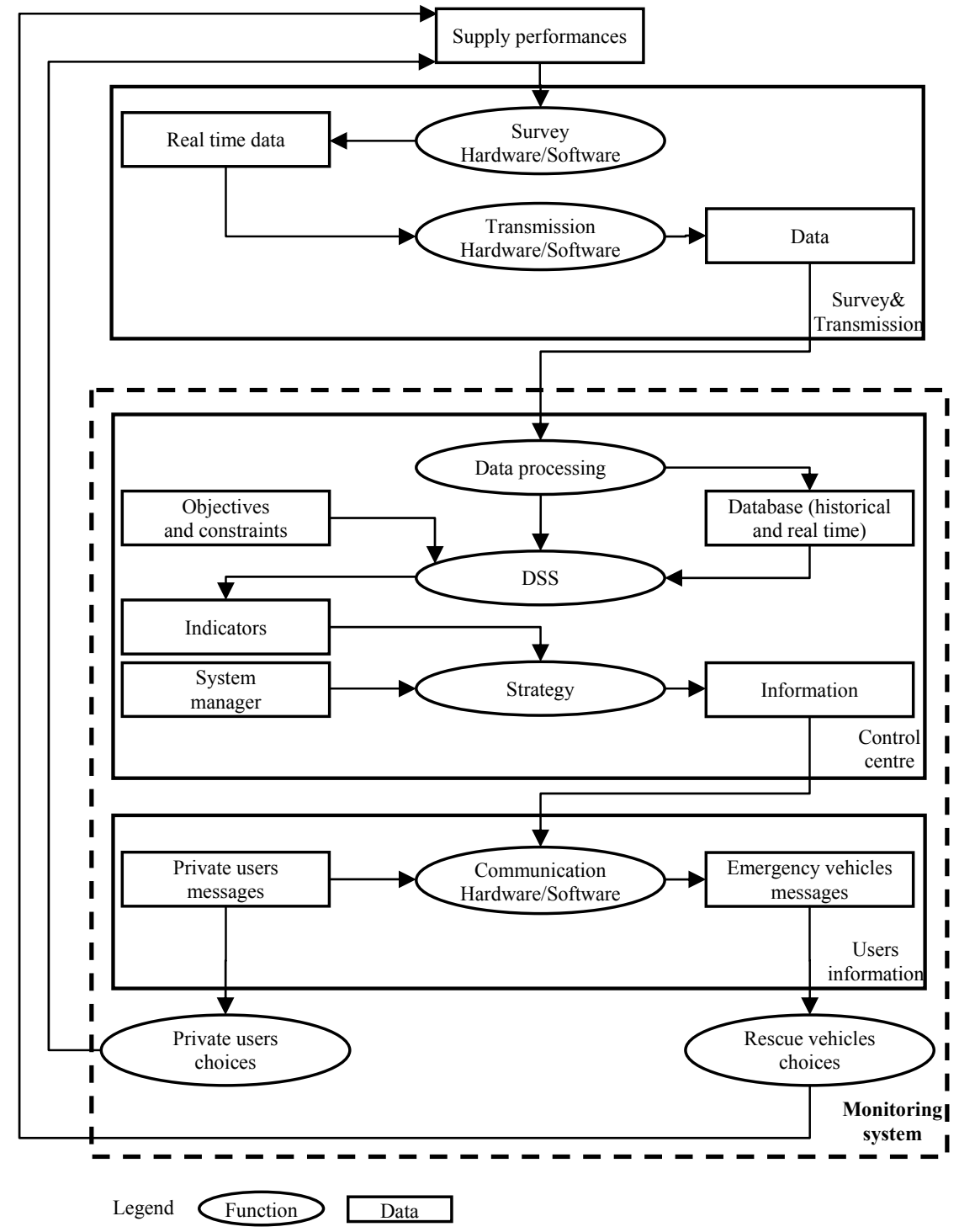

Figure 1: $\quad$ ITS for monitoring and management. 
Each functional class defined above answers to a specific user need: ITS for survey and transmission allows carrying out survey and transmission; ITS for control allow data processing and elaboration of strategies; ITS for users information allow data communication. Survey and transmission, data processing and strategies elaboration, and data communication are explained through some functions. Table 1 proposes a classification of the main functions associated with each considered user need. Users' needs and functions in Table 1 are reported considering user needs and functions defined in ARTIST [1].

Table 1: $\quad$ User needs and functions.

\begin{tabular}{|c|c|}
\hline User needs & Functions \\
\hline $\begin{array}{l}\text { Survey and } \\
\text { transmission }\end{array}$ & $\begin{array}{ll}\text { - } & \text { Collect Traffic Data } \\
\text { - } & \text { Detect Incidents } \\
\text { - } & \text { Monitor Urban Car Park Occupation } \\
\text { - } & \text { Track Traveller and Implement Trip Plan } \\
\end{array}$ \\
\hline $\begin{array}{l}\text { Data processing and } \\
\text { strategies elaboration }\end{array}$ & $\begin{array}{ll}\text { - } & \text { Assess Incidents and Determine Responses } \\
\text { - } & \text { Evaluate Trip } \\
\text { - } & \text { Manage Incidents } \\
\text { - } & \text { Manage Traffic Data } \\
\text { - } & \text { Provide Demand Management Operator Interface } \\
\text { - } & \text { Provide Traffic Control } \\
\text { - } & \text { Provide Traffic Forecasts and Strategies } \\
\text { - } & \text { Provide Traffic Lane Management } \\
\text { - } & \text { Provide Traffic Management } \\
\end{array}$ \\
\hline Data communication & $\begin{array}{ll}- & \text { Assess Perturbations } \\
\text { - } & \text { Guide Traveller } \\
\text { - } & \text { Inform Traveller } \\
\text { - } & \text { Support Trip } \\
\end{array}$ \\
\hline
\end{tabular}

The remaining part of the paper is articulated as follows. Section 2 describes ITS for survey and transmissions. Section 3 describes ITS for control in relation to traffic assignment. Section 4 describes ITS for users information. Some conclusions are drawn in section 5.

\section{ITS for survey and transmission}

Different ITS for survey and transmission are present in literature. In this section a general review is proposed with a focus on ITS used for route survey.

In relation to the general classification proposed in [1], ITS for Survey and Transmission belong to the ATMS (Advanced Traffic Management Systems). ATMS oriented to route choice are recalled.

1. Traffic Monitoring Systems: Closed Circuit Television (CCTV), Automatic Incident Detection (AID), Automatic Vehicle Location (AVL), Automatic Tunnel Control (ATC), Electronic Toll Sensor (ETS). 
2. Urban Traffic Control (UTC): Real Time Traffic Adaptive Signal Control (RTTRACS), Advanced Traffic Control Systems (ATCS), Mapping Info Centre (MIC), Traffic Limited Zone control (ZTL), Parking Management Systems (PMS).

3. Systems Management of Extra Urban Traffic: Automated Highway Systems (AHS), Freeway Traffic Management Systems (FTMS).

Regarding ITS for survey attention is focused on the class related to traffic monitoring systems, which are generally based on vehicles counting, operated by manual or automatic approach. The manual approach is the simplest one but it is affected by human limits which do not allow long-term continuous and accurate surveys. Therefore the manual approach is generally used for short term surveys. Automatic monitoring system provides data not affected by human errors. However it is present an error depending on the characteristic of the technique adopted to detect vehicles. The automatic monitoring system is generally composed by a peripheral survey station, in proximity to the traffic scene, and a transmission system [7]. In the peripheral survey station, composed by sensors, able to detect traffic data, an interpreter, able to receive and decrypt data acquired by sensors (like an image processor, a traffic counter) located and a personal computer, able to store and transmit data to the remote station. Sensors may be classified according to two criteria:

1. the installation procedure:

a. intrusive (pneumatic tubes, inductive loops, piezoelectric sensors; magnetic sensors, ...);

b. non-intrusive (video sensors, acoustic sensors, ...)

2. the extension of the monitored area:

a. tripwire, the monitoring scene is a road section;

b. vehicle tracking, the monitoring scene is a road link.

In relation to vehicles route survey, Automatic Vehicle Location systems (AVL) are able to provide information on route followed by vehicles on the network. For example a palmtop provided by GPS detector is able to provide real time updated information on successive vehicles routes. .Other technologies able to communicate vehicle position are GSM modem, Wi-Fi, radio frequencies based systems.

Surveillance effectiveness is influenced by the way sensors are distributed on the network. In [8] an optimization model is proposed with the aim to find optimal sensors localization.

Regarding ITS for transmissions (the second component of the automatic monitoring system), two main possibilities are available: off-line and on-line. Off-line data include time-varying O-D flows, path choice model and cost function parameters: historical database consist of off-line data. On-line data are typically vehicular flows, speeds and travel times, which are made available by the use of ITS technologies: on-line data describe the current condition of the network, capturing unplanned situation.

The widespread of technologies like mobile, GSM, internet made possible online data transmission. Communication technologies development allowed data transmission from the peripheral survey station to the remote station in real time. 
The remote station receives data (off-line or on-line) acquired from the peripheral survey station. Data are stored in a data-base and are processed in order to update historical data-base. On-line data allow adjusting DTA model parameters in order to obtain DTA model outputs which approximate on-line data $[9,10]$.

During evacuations, traffic counting devices help to provide information on the progress of the evacuation and on the number of vehicles which are evacuating [11]; but automatic systems could be damaged and transmission systems could not be reliable. Enhancing technologies reliability during evacuations could allow collecting on-line data to be used for DSS calibration, while emergency is occurring, and to analyse users' behaviour in non-ordinary situations, when emergency is over. Redundant power sources have been introduced in the USA to support ITS so that they will work although the primary power source is damaged because of the emergency occurring. Some CCTV was equipped with solar power or battery and wireless communication systems make possible data transmission to the control centre [11]. A summary of ITS for survey and transmission is provided in Figure 2.

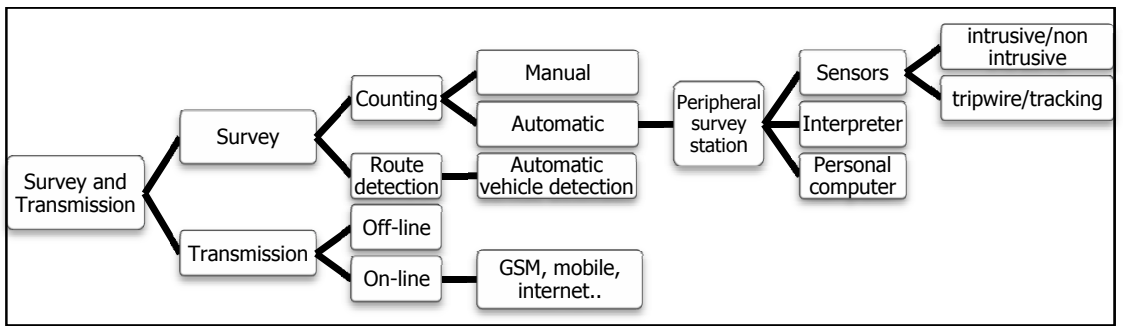

Figure 2: $\quad$ ITS for route Survey and Transmission.

\section{ITS for control}

The second component of ITS provides support to decision makers [12-16]. ITS for control able to reproduce route choice in dynamic conditions, require off-line and on-line data on network flows and chosen routes as inputs. Outputs obtained may be strategies to be applied by authorities and/or information to be communicated to users (like route guidance). As inputs vary, outputs got from ITS for control application change. This feature make ITS for control able to reproduce route choice in dynamic conditions. Two kinds of ITS for control can be distinguished: descriptive approach, optimization approach.

In relation to the optimization approach, departure time, trip destination, transport mode and route $[17,18]$ may be designed.

ITS for control belonging to the first class are called Decision Support Systems (DSS).

In relation to ITS for control, two categories are identifiable:

- DSS which simulate travel demand [19-23];

- DSS which simulate transport supply [25] and travel demand-transport supply interaction. 
In relation to DSS for demand, a demand analysis for transportation system simulation in emergency conditions is proposed in [19]. Specification and calibration of generation and distribution with modal choice models are treated: both SP (Stated Preference) and RP (Revealed Preference) surveys were used.

DSS for demand-supply interaction may have a key role when non-ordinary conditions occur. They may incorporate static and/or dynamic traffic assignment (DTA) models.

In the following DSS which assume DTA models are considered in relation to emergency conditions.

DTA models started to be developed in USA after the partial meltdown of the reactor at the Three Mile Island nuclear power plant in 1979. In the 1980s a first generation of models which support evacuation planning was developed.

After 9/11, great efforts were made to develop dedicated DSS, able to simulate transportation systems in emergency conditions. Research received a new impetus and a second generation of models was developed. Increasing computational burdens allowed the use of microscopic and mesoscopic models on wide networks in emergency conditions. A summary of DSS available, classified in relation to the spatial scale and in relation to conditions in which were specified (Ordinary or Evacuation), is proposed in Figure 3 (see for details [27]).

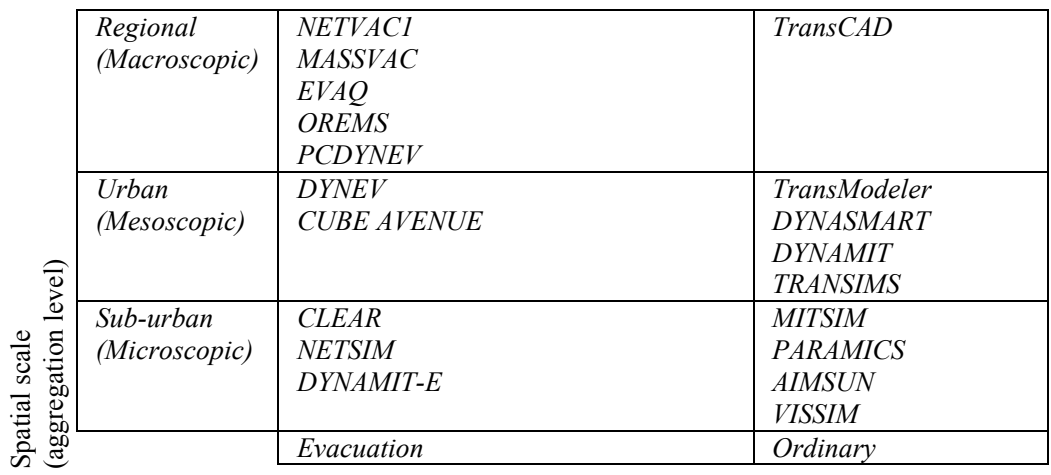

Figure 3: Classification of DSS for demand-supply interaction (source: [27]).

In addition to this the compliance problem has to be considered. One of the main issues is related to the will of users who receive information under emergency conditions, to actually follow behavioural instructions. Generally full compliance is assumed. EVAQ and DYNAMIT take into account the compliance level. In several works [28-30] it is shown that evacuation results increase when a proper level of compliance is used.

The most appropriate DSS has to be chosen in relation to the spatial scale of analysis, the outputs aggregation desired and the time gap available before the disaster occurs.

In Houston [11] and Pel et al. [30] is proposed a classification of ITS for control in relation to supply model, assignment model, user needs, performance 
indicators and ITS functions for d-o interactions. In [31] DSS are classified according to some criteria: traffic assignment model (static or dynamic), approach used (macroscopic, mesoscopic or microscopic), supply model used (link and node cost function specification), path choice model, input needs, indicators provided as output (link indicators, demand-supply interaction indicators, system evolution indicators).

The optimization approach is used in [32]: an optimal spatio-temporal evacuation model and tool is developed, in order to provide users with any route guidance during the evacuation process, supporting the choice [32] is related to demand optimization.

Approaches proposed in the following are related to supply optimization, particularly to network topology design. A procedure to design an optimal contraflow strategy is described in [33]: contraflow is an optimization strategy which allows a re-design of the available network capacity in order to help people to evacuate the emergency area. Contraflow operation also called lane reversals "involves the use of one or more lanes of inbound travel for traffic movement in the outbound direction" [34].

In [35] an optimal zone-based strategy to evacuate users is proposed. A simulation-optimization framework is proposed: the cell transmission model is introduced in order to modeling the traffic flow.

A summary of ITS for control is provided in Figure 4.

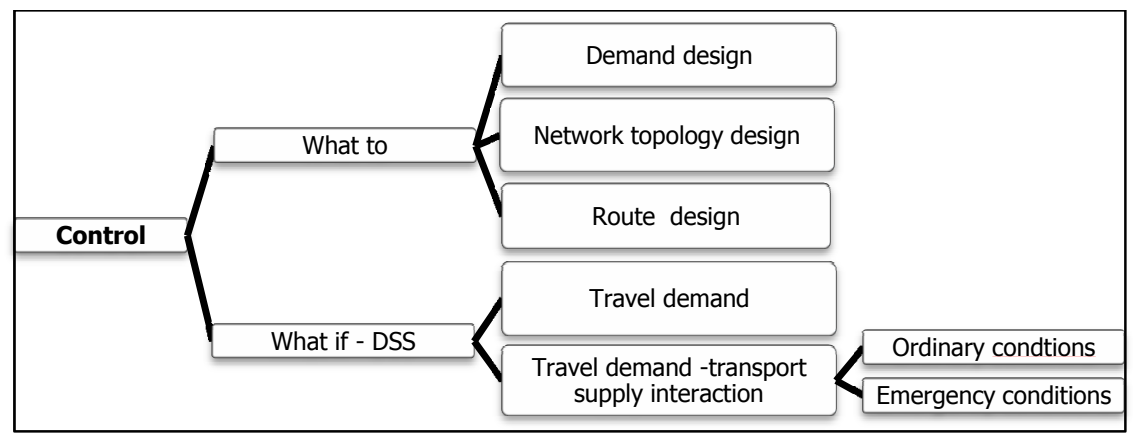

Figure 4: $\quad$ ITS for control.

\section{ITS for communication}

In this section a general review of existing ITS for communication is proposed. In relation to the general classification proposed in [1], ITS for communication belongs to the ATIS (Advanced Traveller Information Systems) class. This class of ITS help users during the travel planning phase in order to avoid congested paths, define departure times, route choice and so on. ATIS is composed by five groups. In the following ATIS groups interesting for route choice application are described.

1. pre-trip information systems for road users: Radio Data System/Traffic Message Channel, Internet, Videotel, Televideo (RDS/TMC), Road Weather 
Information Systems (RWIS), Short Message Services (SMS), Wireless Application Protocol (WAP), Wireless Fidelity (Wi-Fi).

2. en-route information systems for road users: Driver Advisory Service (DAS), Radio Data System/Traffic Message Channel (RDS/TMC), Variable Message Sign (VMS), Global System for Mobile Communication (GSM), Wireless Application Protocol (WAP).

3. public transport information systems: Internet; Videotel, Televideo, Short Message Services (SMS), Wireless Application Protocol (WAP), intelligent poles, information kiosks, on-board systems.

4. integrated information systems to support multimodality: Integrated Transport Information Systems (ITIS), Multimodel Traveler Information Systems (MTIS).

Reliability of ITS for communications is a key element. In emergency conditions some ITSs for communication, generally available in ordinary conditions, may not work: for example VMS may be useless, because of power source unavailability, and mobile phones communications, because of damages in the telecommunication system. Therefore, ITS for communication specifically oriented to emergency conditions are available:

- $\quad$ highway advisory radio (HAR), which can be used to broadcast information to users in localized area using the AM radio band;

- dial 511 systems, which provide information about traffic conditions and weather;

- $\quad$ loud speakers, which broadcast information about routes to be followed;

- $\quad$ siren systems, to alert people to begin immediately standard procedure;

- $\quad$ reverse 911, which allows government agencies to send thousands of calls in 30 minutes to alert residents;

- roadside informers, which provide information to users in relation to the actual network condition;

- Emergency Alert System (EAS), which allows the President communicating immediately using AM, FM, low-power FM, TV broadcast stations, cable systems, wireless cable systems;

- $\quad$ dedicated radio frequencies used specifically during emergency;

- call centres and hotline, which answer questions from users in relation to network condition;

- $\quad$ in-vehicle systems, based on Global Position System (GPS).

In order to classify ITS for communication, three degrees of reliability are introduced: low, medium and high (Table 2).

All systems described may be used to give descriptive or prescriptive information in relation to route to be followed or not by users. ITS for communication may provide pre-trip and/or en-route information (Table 3).

In relation to ITS for communication in emergency conditions, a specific issue is related to users' compliance. In [36] influence of new information sources, like mobile phones, in-car systems such as GPS, and the Internet, is investigated. Users prefer the last sources because of their low implementation cost. Therefore a revision of emergency transportation information communications plans may be required. 
Table 2: $\quad$ Reliability of ITS for communication.

\begin{tabular}{cll}
\hline \multicolumn{1}{c}{ Type } & ITS for communication & Degree of reliability \\
\hline \multirow{3}{*}{ Telephone line } & Call centres and hotline & Low \\
& Dial 511 & Low \\
& Reverse 911 & Low \\
\hline \multirow{2}{*}{ Television } & Televideo & Low \\
& TV broadcasts & Low \\
\hline \multirow{2}{*}{ Mobile } & Mobile phones & Medium \\
& GSM & High \\
\hline \multirow{3}{*}{ Global Network } & Internet & Medium \\
& WAP & $?$ \\
& Wi-Fi & $?$ \\
\hline \multirow{3}{*}{ On road systems } & VMS & Low \\
& Siren systems & Medium \\
& Roadside informers & High \\
& Loud speakers & High \\
\hline In vehicle systems & In-vehicle (GPS) & High \\
\hline \multirow{2}{*}{ Radio } & Dedicated radio frequencies & High \\
& HAR & High \\
\hline
\end{tabular}

Table 3: $\quad$ Pre-trip/En-route information by ITS for communication.

\begin{tabular}{lll}
\hline Pre-trip & En-route & Pre-trip and En-route \\
\hline Televideo & HAR & Call centres and hotline \\
TV broadcasts & In vehicle systems & Dedicated radio frequencies \\
& Loud speakers & Dial 511 \\
& Reverse 911 & EAS \\
& Roadside informers & Internet \\
& Siren systems & Mobile phones \\
& VMS & \\
\hline
\end{tabular}

Mobile phones were used to provide information to users and to communications between users and emergency managers: in 2005 during London subway bombing photos made using mobile cameras were sent to emergency responders in order to alert them [11].

Nowadays internet is available from mobile phones; therefore information can be communicated via e-mail and social networks, reaching quickly a large number of users. Traffic congestion and incidents which may occur during evacuation may induce users to leave previously planned evacuation routes. In Robinson and Khattak [37] detours of some users are prevented by means of a decision-making model.

\section{Acknowledgement}

Research partially supported by national MIUR under PRIN2009, grants n. 2009EP3S42_001. 


\section{References}

[1] Russo F. and A. Quattrone, ITS - Sistemi di Trasporto Intelligenti. Elementi di base e applicazioni operative per il trasporto privato, per il trasporto pubblico, per il trasporto merci e la logistica. FrancoAngeli, Milano, 2010.

[2] Russo F. and A. Vitetta, Reverse assignment: calibrating link cost functions and updating demand from traffic counts and time measurements. Inverse Problems in Science and Engineering 19 (7), pp. 921-950, 2011.

[3] Russo, F., and A. Vitetta. An assignment model with modified logit, which obviates enumeration and overlapping problems, Transportation, vol. 30, pp. 177-201, 2003.

[4] Quattrone A and Vitetta A., Random and fuzzy utility models for road route choice, Transportation Research Part E, Volume 47, Issue 6, November 2011, pp. 1126-1139, 2010.

[5] Ottomanelli M., Dell'Orco M. and Sassanelli D., Modelling parking choice behaviour using possibility theory. Transportation Planning and Technology 34 (7), pp. 647-667, 2011.

[6] Russo F. and Vitetta A., Risk evaluation in a transportation system. International Journal of Sustainable Development and Planning, 1 (2), pp. 170-191, 2006.

[7] Iera A., Modafferi A., Musolino G. and Vitetta A. An experimental station for real-time traffic monitoring on an urban road. In the IEEE $5^{\text {th }}$ International Conference on Intelligent Transportation Systems, 2002.

[8] Yanfeng, O. and Xiaopeng L., Reliable Traffic Sensor Deployment under Probabilistic Disruptions and Generalized Surveillance Effectiveness Measures. In 90th Annual Meeting of the Transportation Research Board, 2011.

[9] Musolino G. and Vitetta A., Short-term forecasting in road evacuation: calibration of a travel time function. In: Brebbia C. A., Pratelli, A. Eds, Urban Transport and the Environment in the 21st century, WIT Press, Southampton, 2011.

[10] Marcianò F.A., Musolino G. and Vitetta A., Within day traffic assignment and signal setting in road evacuation: a procedure with explicit path enumeration. WIT Transactions on the Built Environment, Volume 117, Safety and Security engineering IV, Guarascio M., Reiners G., Brebbia C. A. \& Garzia F. (ed.), WIT Press, Southampton, pp. 403-414, 2011.

[11] Houston N., Routes to Effective Evacuation planning primer series: Using Highways during notice Evacuations operations.

[12] Russo F. and Rindone C., Safety of users in road evacuation: planning internal processes and guidelines. WIT Transactions on the Built Environment, Volume 96, Urban Transport XIII, Urban Transport and the Environment in the 21st century, Brebbia C. A. (ed.), WIT Press, Southampton, pp. 825-834, 2007.

[13] Russo F. and Rindone C., Safety of users in road evacuation: the logical framework approach in evacuation planning. WIT Transactions on the Built 
Environment, Volume 101, Urban Transport XIV, Urban Transport and the Environment in the 21st century, Brebbia C. A. (ed.), WIT Press, Southampton, pp. 751-760, 2008.

[14] Russo F. and Rindone C., Safety of users in road evacuation: Modelling and DSS for LFA in the planning process. WIT Transactions on Ecology and the Environment, Volume 120, Sustainable Development and Planning IV, vol.1, Brebbia C. A. (ed.), WIT Press, Southampton, pp. 453-464, 2009.

[15] Russo, F. and Rindone C., Planning in road evacuation: classification of exogenous activities. WIT Transactions on the Built Environment, Volume 116, Urban Transport XVII, Urban Transport and the Environment in $21^{\text {st }}$ Century, Pratelli \& Brebbia C. A. (ed.), WIT Press, Southampton, pp. 639651, 2011.

[16] Russo, F. and Rindone C., The planning process and logical framework approach in road evacuation: a coherent vision. WIT Transactions on the Built Environment, Volume 117, Safety and Security engineering IV, Guarascio M., Reiners G., Brebbia C. A. \& Garzia F. (ed.), WIT Press, Southampton, pp. 415-425, 2011.

[17] Polimeni A. and Vitetta A., Dynamic vehicle routing in road evacuation: a model for route design. WIT Transactions on the Built Environment, Volume 116, Urban Transport XVII, Urban Transport and the Environment in 21st Century, Pratelli \& Brebbia C. A. (ed.), WIT Press, Southampton, pp. 627-638, 2011.

[18] Polimeni A. and Vitetta A., Dynamic vehicle routing in road evacuation: route design experimentation. WIT Transactions on the Built Environment, Volume 117, Safety and Security engineering IV, Guarascio M., Reiners G., Brebbia C. A. \& Garzia F. (ed.), WIT Press, Southampton, pp. 391-402, 2011.

[19] Russo F. and Chilà G., Safety of users in road evacuation: demand models. WIT Transactions on the Built Environment, Volume 96, Urban Transport XIII, Urban Transport and the Environment in the 21st century, Brebbia C. A. (ed.), WIT Press, Southampton, pp. 773-782, 2007.

[20] Russo F. and Chilà G., Safety of users in road evacuation: RP vs. SP surveys in demand analysis. WIT Transactions on the Built Environment, Volume 101, Urban Transport XIV, Urban Transport and the Environment in the 21st century, Brebbia C. A. (ed.), WIT Press, Southampton, pp. 703$713,2008$.

[21] Russo F. and Chilà G., Safety of users in road evacuation: Modelling and DSS for demand. WIT Transactions on Ecology and the Environment, Volume 120, Sustainable Development and Planning IV, vol.1, Brebbia C. A. (ed.), WIT Press, Southampton, pp. 465-474, 2009.

[22] Russo F. and Chilà G., Demand models in road evacuation: a synopsis of recent contributions. WIT Transactions on the Built Environment, Volume 116, Urban Transport XVII, Urban Transport and the Environment in $21^{\text {st }}$ Century, Pratelli \& Brebbia C. A. (ed.), WIT Press, Southampton, pp. 601614, 2011. 
[23] Russo F. and Chilà G., A statistical approach to analyse user behaviour in road evacuation. WIT Transactions on the Built Environment, Volume 117, Safety and Security engineering IV, Guarascio M., Reiners G., Brebbia C.A. \& Garzia F. (ed.), WIT Press, Southampton, pp. 377-390, 2011.

[24] Mahamassani H, Dynamic network traffic assignment and simulation methodology for advanced system management applications, 2001.

[25] Praticò, F.G. and Moro A., Permeability and volumetrics of porous asphalt concrete: a theoretical and experimental investigation, Road Materials and Pavement Design, vol. 8/4, 2007.

[26] Rathi, A.K., and A.J. Santiago. The new NETSIM simulation model. Traffic Engineering and Control, 31 (5), pp. 317-320, 1990.

[27] Vitetta A., Musolino G. and Marcianò F.A., Safety of users in road evacuation: Modelling and DSS for transport supply and supply-demand interaction. WIT Transactions on Ecology and the Environment, Volume 120, Sustainable Development and Planning IV, vol.1, Brebbia C. A. (ed.), WIT Press, Southampton, pp. 475-484, 2009.

[28] Ben Akiva M., Koutsopoulos H., Antoniou C. and Balakrishna R., Traffic Simulation with DynaMIT, In Fundamentals of traffic simulation (ed. Barcelò), International series in Operations Research \& Management Science 145. 2010

[29] Pel A. J., Hoogendoorn S.P. and Bliemer M.C.J., Evacuation modelling including traveler information and compliance behaviour, Procedia engineering Elsevier press, 2010.

[30] Pel A. J., Hoogendoorn S.P. and Bliemer M.C.J., Impact of variations in travel demand and network supply factors for evacuation studies, In The 89th Annual Meeting of the Transportation Research Board, 2010.

[31] Hardy M. and Wunderlich, K, Evacuation Management Operations (EMO) Modelling Assessment: transportation modelling inventory. Technical Report, 2007.

[32] Abdelgawad, H. and Abdulhai B., Managing Large - Scale Multimodal Emergency Evacuations. Journal of transportation Safety and Security, 2010.

[33] Tuydes, H. and A. Ziliaskopoulos, Tabu-Based Heuristic for Optimization of Network Evacuation Contraflow. In The 85th Annual Meeting of the Transportation Research Board, 2006.

[34] Wolshon B., "One-way-out': contraflow freeway operation for hurricane evacuation, Natural hazards review, 2001.

[35] Zheng, H., Y.C. Chiu and P. Mirchandani, and M. Hickman, Modeling of Evacuation and Background Traffic for an Optimal Zone-Based Vehicle Evacuation Strategy. In the 89th Annual Meeting of Transportation Research Board, 2010.

[36] Robinson R. M. and A. Khattak, Traffic Information Source Selection and Use in Emergency Situations, In the 91th Annual Meeting of Transportation Research Board, 2012. 
[37] Robinson R. M. and A. Khattak, Route change Decision-making by Hurricane Evacuees Facing Congestion, In the 89th Annual Meeting of Transportation Research Board, 2010. 